\title{
DISCRIMINATION AND EMISSION OF TEMPORAL INTERVALS BY PIGEONS ${ }^{1}$
}

\author{
G. S. REYNOLDS
}

THE UNIVERSITY OF CHICAGO

\begin{abstract}
Because the frequency distribution of IRTs showed little or no control by a DRL schedule, the schedule was modified so that the pigeon's behavior after each IRT would indicate whether or not it had discriminated the duration of the IRT. After every two pecks on a red key, the key changed to blue for $30 \mathrm{sec}$. Then it automatically became red again. Pecks on the blue key were reinforced with food on a VI schedule only when the preceding IRT on the red key had been longer than $18 \mathrm{sec}$. The birds did not selectively emit longer IRTs on the red key: the value of IRTs/op did not increase with IRT duration. However, they did discriminate the duration of the IRT emitted on the red key: the rate of pecking on the blue key was an increasing function of the duration of the preceding IRT on the red key.
\end{abstract}

Pigeons do not perform well on their first exposure to a DRL schedule of reinforcement of about $20 \mathrm{sec}$ duration. They emit many short interresponse times (IRTs), which are never reinforced, and few long IRTs, which are always reinforced (Reynolds and Catania, 1961; Reynolds, 1964; Staddon, 1965).

The present study asks whether the failure to emit longer IRTs consistently is caused by a failure to discriminate between IRTs of different durations. The procedure reinforces only long IRTs, as in the DRL. In addition, after each IRT the bird indicates by its behavior whether or not it discriminates the duration of the preceding IRT.

\section{METHOD}

\section{Subjects}

Three, adult male, white Carneaux pigeons were maintained at $80 \%$ of their free-feeding weights.

\section{Apparatus}

A standard operant conditioning chamber contained a magazine for delivering grain for 3.5 sec (reinforcement), dim overhead illumination, a supply of drinking water, a white masking noise, and a response key of $3 / 4^{-i n}$. diameter located on the wall above the maga-

\footnotetext{
${ }^{1}$ Research supported by grants GB-916 and GB-2541 from the National Science Foundation to the University of Chicago. Reprints may be obtained from the author, Department of Psychology, The University of Chicago, Chicago, Illinois 60637.
}

zine and operated by an effective force of about $15 \mathrm{~g}$. The key was transilluminated from behind with red or blue light. Programming and recording equipment was separated by one room from the chamber.

\section{Procedure}

A maintained gradient of generalization was arranged with the duration of an IRT as the stimulus continuum. It is a modification of a previous procedure for studying temporal generalization (Reynolds and Catania, 1962). In the previous procedure the temporal stimulus was specified by the apparatus. A dark key was presented for various periods of time preceding a lighted key of $30 \mathrm{sec}$ duration. Pecking on the lighted key was reinforced only if the duration of the preceding dark interval had been longer than a certain value. In the present procedure, the temporal stimulus is specified by the pigeon's IRT. The bird pecks twice on a red key. The second peck changes it to blue for $30 \mathrm{sec}$. After $30 \mathrm{sec}$, the color automatically changes back to red, whether or not pecks on the blue key occur. Two more pecks on red again change the key to blue for $30 \mathrm{sec}$. This sequence occurred 200 times in each daily session. Pecks during the $30 \mathrm{sec}$ of blue illumination were reinforced only when the blue key followed two pecks on the red key that were separated by $18 \mathrm{sec}$ or more. Pecks on the blue key were never reinforced if the preceding two pecks on the red key were separated by less than $18 \mathrm{sec}$. Thus, the IRT on the red key 
provides values on a stimulus continuum, after only some of which is pecking reinforced. The procedure was in effect for 103 sessions.

Reinforcement of pecks on the blue key was on a VI schedule with an average interval of $1 \mathrm{~min}$. Observation showed that the occurrence of the reinforcer was not a confounding discriminative stimulus.

Two sets of numbers were recorded: first, the frequency of occurrence of IRTs on the red key, in 3-sec class intervals, giving the frequency of exposure to various values of the temporal stimulus, and second, the total number of pecks on the blue key, recorded separately for each 3-sec class interval of IRT duration on the preceding red key. Dividing the second by the first set gives the number of responses per 30-sec exposure to the blue key as a function of the duration of the preceding IRT on the red key. Dividing the frequency in each class interval in the first set by the frequency in that and greater class intervals gives a distribution of IRTs/op over IRT duration for the set of 200 separate IRTs on the red key in the session (Anger, 1956).

There were two subsequent modifications of the procedure. (1) A set of seven white pilot lamps were arranged vertically at the far right side of the front panel of the chamber. Whenever the key changed to blue, one of the lamps was lighted depending, from top to bottom, on the 3-sec class interval of IRT duration in which the preceding IRT on the red key had occurred. Reinforcement continued as before, now in the presence of the bottom pilot lamp. This procedure was in effect for 20 sessions. (2) Pilot lamps were lighted as before during blue key presentations, but now also during presentation of the red. As time elapsed between the two pecks on the red key, successively lower lamps in the array were lighted. This procedure was in effect for 12 sessions.

Finally, after having returned to the original procedure for six sessions, only one peck was required to change the key from red to blue. This is the same as beginning to time the interval from the start of the red key, rather than from the first peck on it. There was only a transient disruption of the performance, indicating that the duration of the red key without an associated IRT was able to control behavior during the blue-key periods. It does not indicate, of course, that the duration of the IRT during red had no control, and since IRTs were measured, the results will be presented in those terms.

\section{RESULTS}

Each row in Fig. 1 shows data for a separate bird from the last session of each procedure. The left column gives the number of IRTs/ op as a function of IRT duration on the red key. The right column gives the rate of responding, relative to its maximum in each function, on the blue key as a function of the preceding IRT on the red key. Circles are from the original procedure, triangles from the modification to include pilot lamps only during the blue key, and squares from the modification to include pilot lamps during both colors.

In the original procedure, without the aid of pilot lamps, the value of IRTs/op is approximately constant over IRT duration (left col., circles), with the exception of the first class interval, 0-3 sec, where it is higher. (On DRL, this class interval typically commands the lowest value of IRTs/op, in pigeons. See, e.g., Reynolds, 1964.) The relative rate of responding, however, is an increasing function of IRT duration (right col., circles). IRTs on the red key are emitted with a constant conditional probability (IRTs/op), but their duration is apparently discriminable.

The effect of introducing, during the blue periods, pilot lamps correlated with the duration of the preceding IRT during red (triangles) is to sharpen the discrimination evident in the relative rate of responding (although only slightly for bird c), but not to change appreciably the function relating IRTs/op to IRT duration.

When the pilot lamp appropriate to elapsed time is lighted between responses during red also (squares), the sharper function of the relative rate of responding continues, and the value of IRTs/op becomes not unexpectedly an increasing function of IRT duration. The exteroceptive stimuli exert the same control over responses on the red key as they had come to exert over responses on the blue key in the preceding procedure.

\section{DISCUSSION}

The pigeons consistently emitted IRTs too short for reinforcement, but they discrimi- 


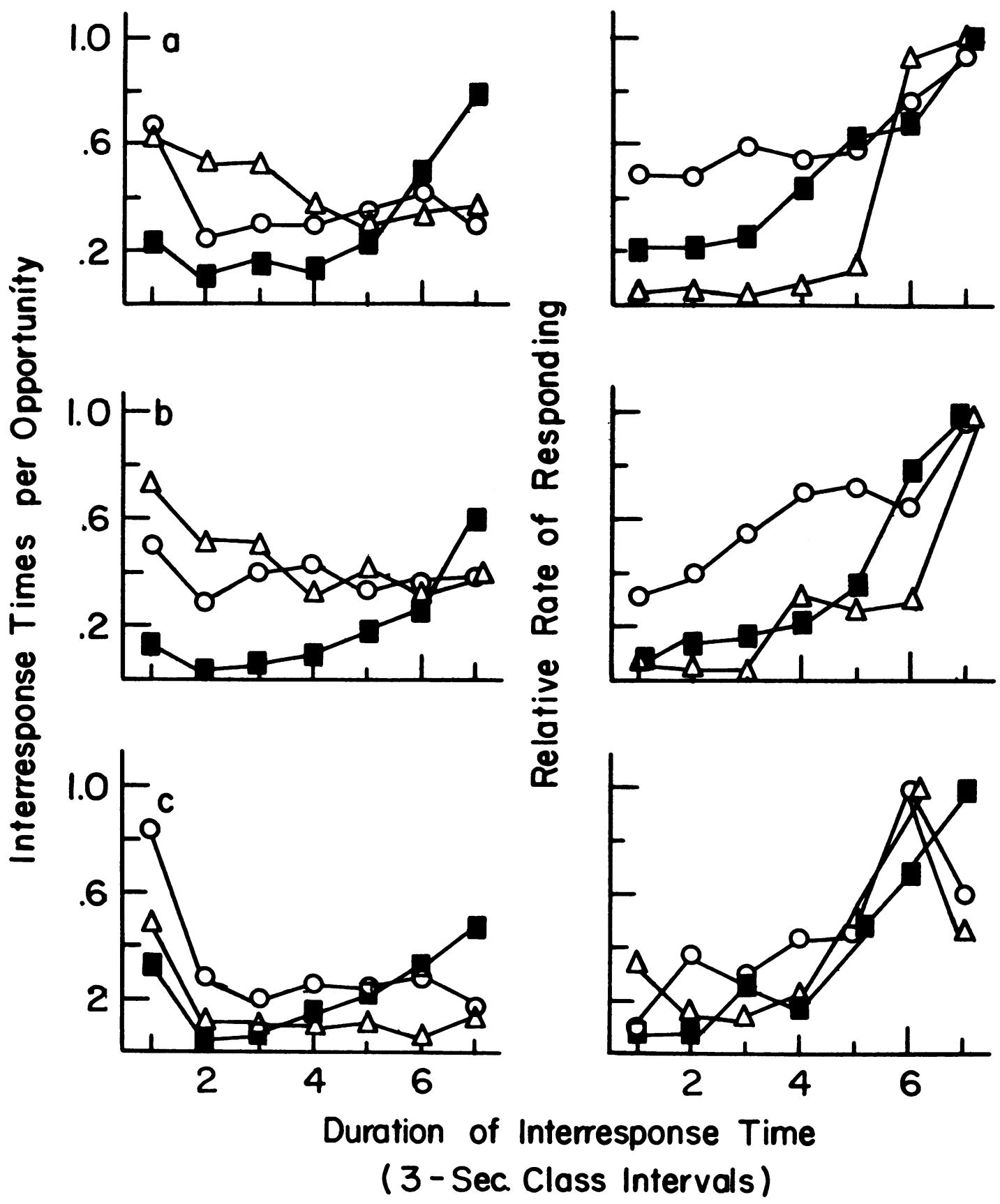

Fig. 1. Each row shows, for a separate bird, in the left graph the number of IRTs per opportunity as a function of the duration of the IRTs emitted on a red key (the second response changed the color to blue for 30 sec), and in the right graph the relative rate of responding on the blue key as a function of the preceding IRT on the red key. The circles show the initial results. The triangles show the results obtained when an added stimulus, whose value depended on the duration of the IRT on the red key, was present during the blue-key periods. The squares show the data when the added stimulus was present during both the red-and blue-key periods.

nated the duration of the IRTs. The duration of the IRT (or of the red-key period) successfully controlled the rate of pecking during the succeeding blue-key periods but did not control the probability of pecking on the red key (IRTs/op). Thus, discrimination along 
the temporal continuum does not assure that the bird will withhold pecks until the time of reinforcement. Nor does a lack of consistent change of IRTs/op with IRT duration necessarily indicate a lack of temporal discrimination.

These conclusions suggest that the pigeon's poor performance on initial exposure to a DRL schedule may not be caused by a failure in temporal discrimination. Temporal discrimination and generalization, like those for color, are probably already built into normal adult birds by nature or by experience before experiments begin. Improved performance, such as that shown by Staddon (1965) after interpolated reinforcement on shorter DRLsa phenomenon likened to learning to learnmay not represent improved temporal discrimination. Exposure to different DRL values and hence to different IRTs required for reinforcement may perhaps direct the birds' attention to time as the dimension of importance in the DRL schedule.

\section{REFERENCES}

Anger, D. G. The dependence of interresponse times upon the relative reinforcement of different interresponse times. J. exp. Psychol., 1956, 52, 145-161.

Reynolds, G. S. Temporally spaced responding by pigeons: development and effects of deprivation and extinction. J. exp. Anal. Behav., 1964, 7, 415-421.

Reynolds, G. S. and Catania, A. C. Behavioral contrast with fixed-interval and low-rate reinforcement. J. exp. Anal. Behav., 1961, 4, 387-391.

Reynolds, G. S. and Catania, A. C. Temporal generalization in pigeons. Science, 1962, 135, 314-315.

Staddon, J. E. R. Some properties of spaced responding. J. exp. Anal. Behav., 1965, 8, 19-27. 